\title{
Coronary Angioplasty with Stent in Woman with Active Vaginal Bleeding
}

Felipe José de Andrade Falcão, ${ }^{1,2}$ Fabiano Lima Cantarelli, ${ }^{2 \oplus}$ Aline Hofmann Baião, ${ }^{2}{ }^{\oplus}$ Marco Rivera, ${ }^{2}{ }^{\oplus}$ Verônica Monteiro, ${ }^{2 \oplus}$ Flavio Roberto Azevedo de Oliveira ${ }^{2}{ }^{20}$

Universidade de Pernambuco,' Garanhuns, PE - Brazil

Instituto de Medicina Integral Prof. Fernando Figueira, ${ }^{2}$ Recife, PE - Brazil

\section{Abstract}

Uterine leiomyoma and coronary artery disease are two common diseases in women. However, the association of uterine bleeding caused by leiomyoma with unstable coronary syndrome is not frequent. Here we describe a case of a patient with active vaginal bleeding and unstable angina who underwent a unique approach by performing percutaneous procedures. The report demonstrates that new interventional options can be used to control active bleeding in patients in need of coronary angioplasty.

\section{Introduction}

Percutaneous transluminal coronary angioplasty (PTCA) with stent requires dual antiplatelet therapy with acetylsalicylic acid and a $\mathrm{P} 2 \mathrm{Y}_{12}$ receptor inhibitor (clopidogrel, ticagrelor or prasugrel). However, this approach increases the risk of bleeding that should always be evaluated since hemorrhagic complications have an adverse impact on prognosis. ${ }^{1}$

Patients with an increased risk of bleeding or with active bleeding usually undergo surgical revascularization since they do not require dual antiplatelet therapy. ${ }^{2}$

We report a case of a patient with uterine leiomyoma with active vaginal bleeding who underwent, during the same surgical session, coronary angioplasty with stenting and uterine embolization.

\section{Keywords}

Embolization Therapeutic; Leiomyoma; Uterine Hemorrhage; Woman; Angioplasty; Stent; Hemorrhage/ complications.

\section{Case report}

Female patient, 42 years old, with uterine leiomyoma, reporting chest pain with sweating on moderate exertion and progressive worsening. The patient had a history of hypermenorrhagia and progressive dysmenorrhea, three previous pregnancies with no complications and tubal ligation. The patient reported hypertension and non-insulin dependent diabetes mellitus (treatment initiated about five years ago) and no lesions in any other target organs.

During the bleeding episode, the patient had chest pain at rest, requiring blood transfusion to stabilize her condition (hemoglobin $7 \mathrm{~g} / \mathrm{dL}$ ). No changes in myocardial necrosis markers or electrocardiogram were observed (unstable angina). Echocardiography showed normal sized heart chambers, left ventricular ejection fraction of 70\% and no changes in segmental contractility.

Cardiac catheterization revealed $90 \%$ stenosis of the medial third of the left anterior descending (LAD). Due to frequent vaginal bleeding wich made the use of dual antiplatelet therapy impossible, myocardial revascularization surgery was performed and a hysterectomy was planned to be done after recovery. The surgery consisted of anastomosis of the left internal thoracic artery (LITA) to the LAD, without extracorporeal circulation, with no complications.

On the seventh postoperative day, the patient had severe vaginal bleeding followed by typical chest pain, hypotension and electrocardiogram showing dynamic T-wave changes in the anterior wall.

A second cardiac catheterization showed occlusion of the medial third of the LITA, and severe stenosis of the medial third of the LAD. Arteriography of the uterine arteries showed artery hypertrophy, coiling of intraparenchymal branches and tumor blush. At this

Mailing Address: Felipe Falcão

Rua Isaac Salazar, 102/902. Postal Code: 52060-105, Recife, PE - Brazil.

E-mail: felipejaf@gmail.com 
same procedure, bilateral embolization of uterine arteries was performed with 500-700 $\mu \mathrm{m}$ polyvinyl alcohol bilateral to control vaginal bleeding, followed by PTCA of the LAD with $3.0 \times 20 \mathrm{~mm}$ non-drug eluting stent (Omega, Boston Scientific Inc., Natick, USA) at 18 atm (Figures 1 and 2), without complications.

The patient showed good clinical response, with significant improvement of bleeding and cardiovascular symptoms until hospital discharge. The patient continued dual antiplatelet therapy for one month. During 150 days of cardiological follow-up, no recurrence of angina was reported. The patient continued gynecological follow-up, an no surgery was required for myomas.

\section{Discusssion}

Women's diseases generally have a temporal relationship with hormone profile. During menstrual period, women tend to develop estrogen-dependent diseases, such as endometriosis and uterine myomas, whereas in the postmenopausal period, hyperlipidemia, coronary artery disease (CAD), among others, are more frequent. Nagai et al., ${ }^{3}$ in a prospective cohort with 49,000 women, identified the age at peak incidence for 20 women's diseases. Peak incidence of uterine myoma was 44.8 years of old, and angina pectoris, 65 . Therefore, the association between these two conditions is not common, with a 20-year difference between their peak of incidence. ${ }^{3}$

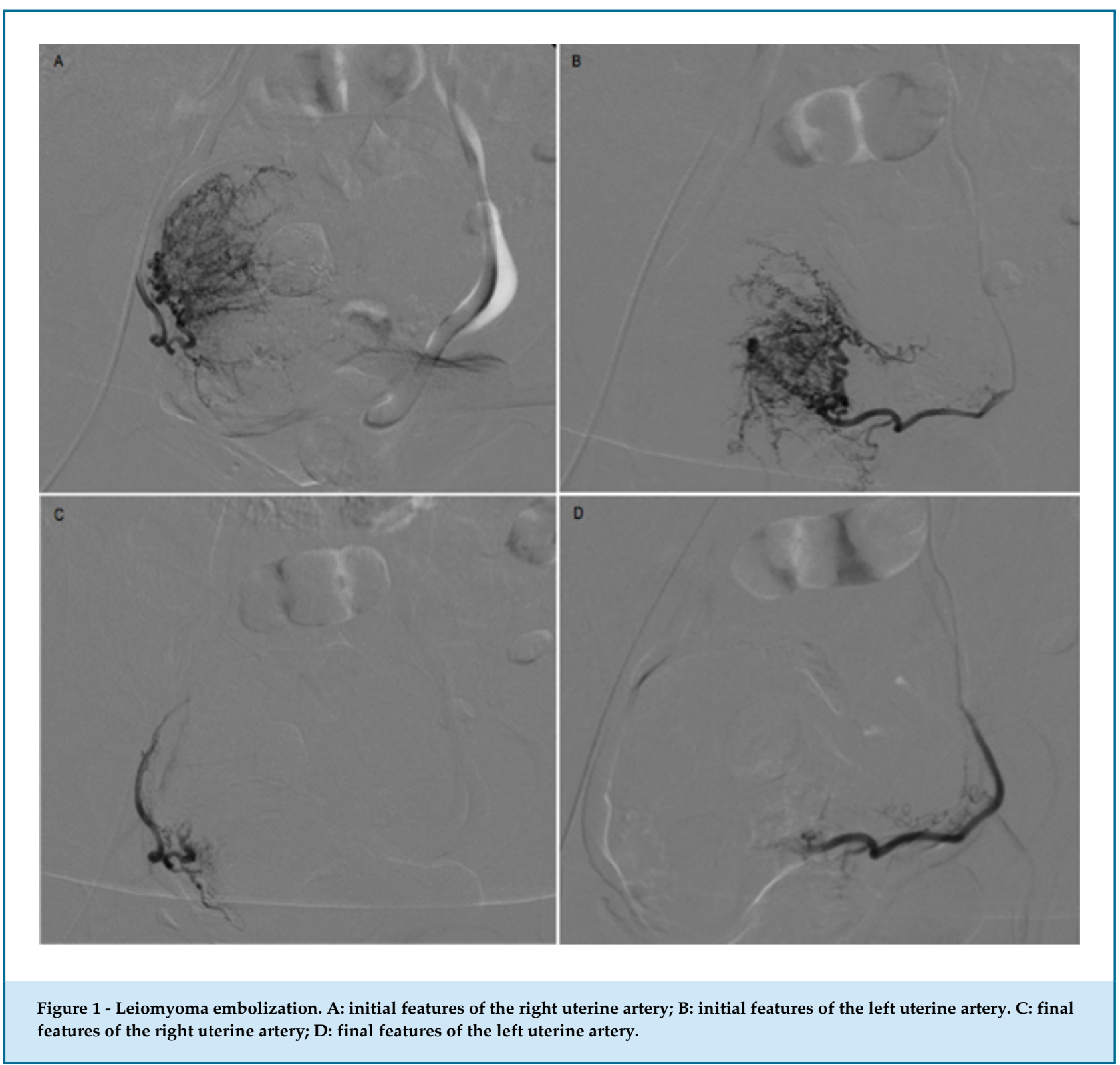



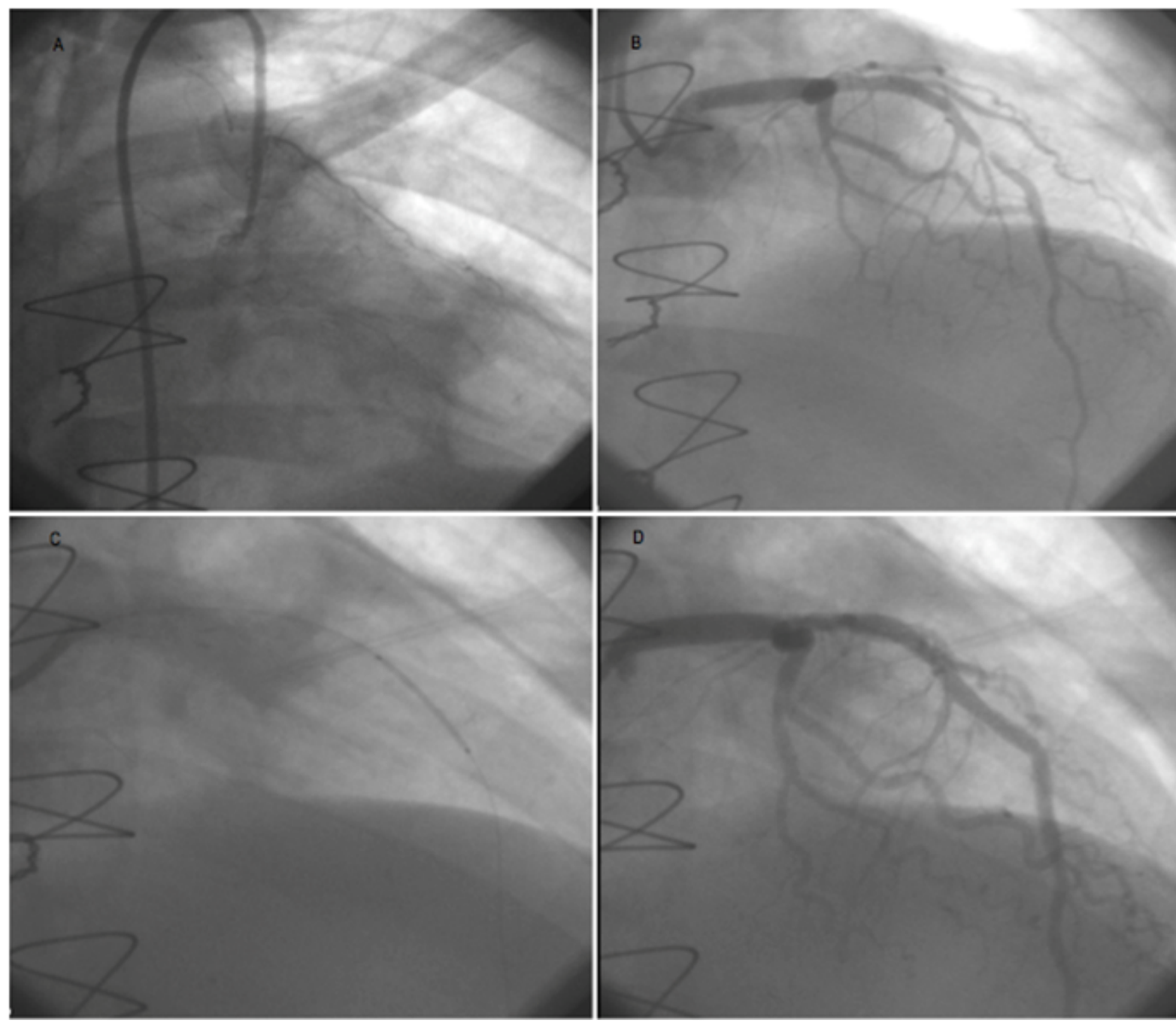

Figure 2 - Coronary angioplasty of left anterior descending artery. A: occlusion in the medial third of the left internal thoracic artery; B: stenosis of the medial third of anterior descending artery; C: stent positioning in the stenosis; D: final result in the left anterior descending artery.

Here we report a case of a 42 year old woman with risk factors for cad other than the age, such as diabetes mellitus and hypertension. In light of the epidemics of obesity, it is expected an earlier onset of cardiovascular diseases in women. Therefore, the association of CAD with estrogen-dependent diseases will be more common.

CAD is one of the main causes of mortality worldwide. Revascularization (PTCA or surgical revascularization) is indicated for patients with stable disease, refractory to clinical treatment, or with acute coronary syndromes. The choice of treatment depends on the analysis of several factors, such as severity of CAD, surgical risk and risk of bleeding. ${ }^{2}$
PTCA has a lower risk of bleeding, but requires antiplatelet therapy. High bleeding risk patients that require PTCA is a challenge. The risk of ischemia should always be evaluated together with the risk of bleeding, and the selection of both the stent type and the antiplatelet therapy regimen depends on such evaluation. ${ }^{4}$ In the case reported, although the coronary stenosis was not complex, the patient was submitted to a surgical procedure. The choice was made because dual antiplatelet after this procedure was not necessary and hysterectomy was already schedule.

Dual antiplatelet therapy is mandatory after stent implantation and recommended to be maintained until 
endothelization of the stent struts occurs. Discontinuation of the therapy before this process increases the risk of stent thrombosis. Although the mechanism of thrombosis has not been fully elucidated, the design of the stent platform, toxicity of antiproliferative drugs and the type of the stent polymer (biodegradable vs. durable polymers) are important factors. In general, antiplatelet therapy should be continued for at least 30 days in a case of conventional stents, and for one year if drug-eluting stents are used. ${ }^{5}$

Hemorrhagic complications in patients undergoing PTCA have been associated with increased risk of adverse events, such as acute infarction, stroke, stent thrombosis and death in patients with acute coronary syndromes and in patients with chronic diseases. Although the exact mechanism of this association is unknown, it may be related to discontinuation of therapies known to increase survival (antiplatelet drugs, beta-blockers), direct effects of blood transfusion, high prevalence of comorbidities of these patients, and deleterious effects of anemia. Thus, the anti-ischemic benefit of any therapy should always be weighed against the risk of bleeding. ${ }^{6-10}$ Advanced age, female sex, chronic renal dysfunction and anemia are clinical predictors of bleeding after percutaneous procedures. The use of bleeding risk scores such as the CRUSADE and the HAS-BLED can make this assessment more effective. ${ }^{11}$

Early failure of arterial graft is not common. Early and long-term patency of the LITA, when anastomosed to the $\mathrm{LAD}$, is of $95 \%$ and $85-90 \%$, respectively. Only $1 \%$ of the patients at the immediate postoperative of myocardial revascularization involving the LITA have symptoms of angina. The most common causes of early graft failure are related to technical issues, such as the anastomosis, since progression of the atherosclerosis in a short time period is unlikely. ${ }^{12,13}$

In our patient, there was occlusion of the medial third of the LITA. Hypotension caused by vaginal bleeding created favorable conditions to occlusion of the LITA. As LITA failure is confirmed, the target of percutaneous revascularization may be the LITA or native coronary bed, depending on atherosclerosis severity. A second surgical approach should be indicated with caution in patients whose anatomy is unfavorable for interventionist procedure. $^{2}$

Uterine leiomyomas, the most common pelvic tumor in women, are benign tumors originating from smooth muscle cells in the myometrium that cause pelvic pain, infertility and vaginal bleeding. Therapeutic options are hormone therapy, surgery (hysterectomy or myomectomy), or interventional procedures (uterine arterial embolization). Less aggressive therapies (myomectomy and embolization) are the therapies of choice for patients who want to get pregnant. Uterine arterial embolization allows reduced hospitalization time and early return to daily activities as compared with surgical procedures. ${ }^{14}$

The case reported exemplifies the combination of two common diseases in female patients that may be successfully treated by percutaneous procedures, with low risk of complications. Control of active bleeding by embolization procedures can be used for patients in need of coronary angioplasty and antiplatelet therapy.

\section{Author contributions}

Acquisition of data: Baião AH, Rivera M, Monteiro V, Oliveira FRA. Analysis and interpretation of the data: Cantarelli FL. Writing of the manuscript: Falcão FJA. Critical revision of the manuscript for intellectual content: Falcão FJA, Oliveira FRA.

\section{Potential conflict of interest}

The authors declare that they have no potential conflict of interest.

\section{Sources of funding}

This study did not have any source of funding.

\section{Study association}

This study has no relationship with any thesis or dissertation.

\section{Ethics approval and consent to participate}

This study was approved by the Ethics Committee of the Instituto de Medicina Integral Prof. Fernando Figueira under the protocol number 4643. All the procedures in this study were in accordance with the 1975 Helsinki Declaration, updated in 2013. Informed consent was obtained from all participants included in the study. 


\section{References}

1. Mehran R, Pocock SJ, Nikolsky E, Clayton T, Dangas GD, Kirtane AJ, et al. A Risk score to predict bleeding in patients with acute coronary syndromes J Am Coll Cardiol. 2010;55(23):2556-66.

2. Windecker S, Kolh P, Alfonso F, Collet JP, Cremer I, Falk V, et al. 2014 ESC/EACTS Guideline on myocardial revascularization: The Task Force on myocardial revascularization of the European Society of Cardiology and the European Association for Cardio-Thoracic Surgery developed with the special contribution of the European Association of percutaneous cardiovascular interventions. Eur Heart J. 2014;35(37):2541-619.

3. Nagai K, Hayashi K, Yasui T, Katanoda K, Iso H, Kiyohara Y, et al. Disease history and risk of comorbidity in women's life course: a comprehensive analysis of the Japan Nurses' Health Study baseline survey. BMJ Open 2015;5(3):e0006360

4. Jensen CJ, Naber CK, Urban P, Onq PJ, Valdes-Chavarri M, Abizaid AA, et al. Two-Year Outcomes of High Bleeding Risk Patients After PolymerFree Drug-Coated Stents: a LEADERS FREE substudy. EuroIntervention 2018;13(16):1946-9.

5. Han $Y$, Jing $Q, X u$ B, Yang L, Liu H, Shang X, et al. Safety and Efficacy of Biodegradable Polymer-Coated Sirolimus-Eluting Stents in "Real-World" Practice : 18-Month Clinical and 9-Month Angiographic Outcomes. JACC Cardiovasc Interv. 2009(4):303-9.

6. Doyle BJ, Rihal CS, Gastineau DA, Holmes DR Jr. Bleeding, blood transfusion, and increased mortality after percutaneous coronary intervention: implications for contemporary practice. J Am Coll Cardiol. 2009;53(22):2019-27.

7. Spencer FA, Moscucci M, Granger CB, Gore JM, Goldberg RJ, Steg PG, et al. Does comorbidity account for the excess mortality in patients with major bleeding in acute myocardial infarction? Circulation. 2007;116(24):2793-801.

8. Wang TY, Xiao L, Alexander KP, Rao SV, Kosiborod MN, Rumsfeld JS, et al. Antiplatelet therapy use after discharge among acute myocardial infarction patients with in-hospital bleeding. Circulation. 2008;118(21):2139-45.

9. Rao SV, Jollis JG, Harrington RA, Granger CB, Newby LK, Armstrong $\mathrm{PW}$, et al. The relationship of blood transfusion and clinical outcomes in patients with acute coronary syndromes. JAMA. 2004;292(13):1555-62.

10. Sabatine MS, Morrow DA, Giugliano RP, Burton PB, Murphy SA, McCabe $\mathrm{CH}$, et al. Association of hemoglobin levels with clinical outcomes in acute coronary syndromes. Circulation. 2005;111(16):2042-9.

11. Subherwal S, Bach RG, Chen AY, Gage BF, Rao SV, Newby LK, et al. Baseline risk of major bleeding in non-ST-segment-elevation myocardial infarction: the CRUSADE (Can Rapid risk stratification of Unstable angina patients Suppress ADverse outcomes with Early implementation of the ACC/ AHA Guidelines) bleeding score. Circulation. 2009;119(14):1873-82.

12. Najm HK, Leddy D, Hendry PJ, Marquis JF, Richardson D, Keon WJ. Postoperative symptomatic internal thoracic artery stenosis and successful treatment with PTCA. Ann Thorac Surg 1995;59(2):323- 7.

13. Marx R, Klein RM, Horlitz M, Ketteler T, Schannwell CM, Lapp H, et al. Angioplasty of the internal thoracic artery bypass-graft an alternative to reoperation. Int J Cardiol.2004;94(2-3):143-9.

14. Stewart EA, Barbieri RL, Falk S. Overview of treatment of uterine leiomyomas(fibrosis). [Internet]. [Cited in 2018 Jan 30]. Available from: https: / / www.uptodate.com/ contents / overview-of-treatment-ofuterine-leiomyomas-fibrosis 